\title{
DESENVOLVIMENTO DE SOFTWARE EM VISUALBASIC PARA GERENCIAMENTO E AQUISIÇÃO DE DADOS DO POLARÓGRAFO
} PAR 384B

\section{ARTIGO ORIGINAL}

REIS, Efraim Lázaro1, GONZAGA, Fabiano Barbieri², REIS, César³ ${ }^{3}$ MAYRINK, Maria Isabel Cristina Batista ${ }^{4}$, CUSTÓDIO, Gislene ${ }^{5}$

REIS, Efraim Lázaro. Et al. Desenvolvimento de software em Visualbasic para gerenciamento e aquisição de dados do polarógrafo PAR 384B. Revista Científica Multidisciplinar Núcleo do Conhecimento. Ano 05, Ed. 12, Vol. 16, pp. 144160. Dezembro de 2020. ISSN: 2448-0959, Link de acesso: https://www.nucleodoconhecimento.com.br/tecnologia/software-em-visualbasic, DOI: 10.32749/nucleodoconhecimento.com.br/tecnologia/software-em-visualbasic

\section{RESUMO}

Foi desenvolvido um software em Visual Basic para controle e aquisição de dados do polarógrafo PAR modelo 384B. Este aparelho é da década de 70, e portanto, com uma eletrônica digital ultrapassada, mas a parte analógica do potenciostáto é muito robusta e permitiu que se prolongasse a vida útil deste instrumento. Isto tornou possível aplicações em aulas de laboratório na determinação de $\mathrm{Cu}(\mathrm{II}), \mathrm{Pb}(\mathrm{II}), \mathrm{Cd}(\mathrm{II})$ e Zn(II) por voltametria de pulso diferencial com redissolução anódica e a titulação amperométrica de $\mathrm{Cu}$ (II) com EDTA usando voltametria de onda quadrada. Nos dois casos o uso do instrumento interfaceado mostrou melhor versatilidade e rapidez em

\footnotetext{
${ }^{1}$ Doutor em Química.

2 Doutor em Química.

${ }^{3}$ Doutor em Química.

${ }^{4}$ Doutora em Bioquímica Aplicada.

${ }^{5}$ Mestre em Agroquímica.
}

RC: 71506

Disponível em: https://www.nucleodoconhecimento.com.br/tecnologia/software-em- 
relação ao processo de obtenção de dados quando se trabalha apenas com o polarógrafo não interfaceado.

Palavras-Chave: Voltametria, VisualBasic, Polarógrafo M384B.

\section{INTRODUÇÃO}

O polarógrafo PAR modelo 384B foi desenvolvido na década de 70 e é completamente controlado por um microprocessador 8085 da INTEL, apresentando internamente uma unidade de disco de 5.1/4", com capacidade de armazenamento de $89 \mathrm{~Kb}$ e com velocidade de comunicação máxima de 9600 bits. O painel frontal incorpora um mostrador alfanumérico e 74 botões de contato para operação e controle (Figura 1A). Portanto como se pode deduzir, é um instrumento obsoleto, quando se trata da parte computacional do mesmo, mas a parte analógica do potenciostáto, apesar de também ser ultrapassada, é muito robusta e o aparelho como um todo pode ter sua vida útil aumentada e ser aproveitado. (EG\&G PARC, 1993)

Os dados nas varreduras em gráficos de corrente versus potencial são registrados em papel com um plotter e apenas os máximos dos picos tem seus valores anotados, de acordo com a programação original do aparelho (Figura 2). Este aparelho não vem com software próprio para interfaceamento a microcomputadores, isto se torna um problema quando se necessita dos dados do voltamograma completo para tratamento posterior.

RC: 71506

Disponível em: https://www.nucleodoconhecimento.com.br/tecnologia/software-em- 
Figura 1. Polarógrafo PAR modelo 384B (A) e cela modelo 303A (B).

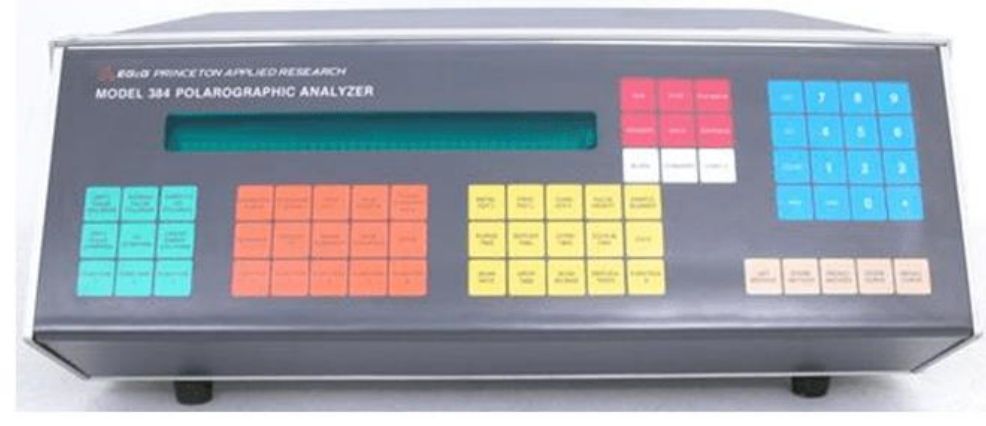

(A)

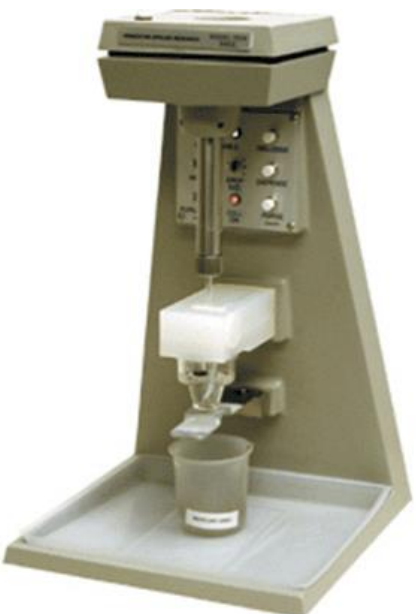

(B)

Fonte: EG\&G, 1993.

Quase todos os comandos disponíveis no painel frontal do instrumento podem ser enviados ao polarógrafo pelo microcomputador, através da interface RS232C, segundo uma tabela de correspondência entre caracteres ASCII e comandos fornecida pelo fabricante. Quando o software interno do polarógrafo recebe um caracter ASCII, ele verifica se o comando é válido, executando o comando na sequência. (EG\&G PARC, 1993)

O polarógrafo em sua configuração usual de fábrica permite a seleção de no máximo três adições de padrões, ou confecção de curvas de calibração com apenas três pontos, isto é uma adição extra além destas três apaga a antecessora na memória. Uma das limitações da forma original de fábrica é que cada voltamograma deve ser impresso através do plotter, não havendo a possibilidade de sobreposição de voltamogramas, o que dificulta a interpretação quando se observa os gráficos, que estão em escalas diferentes.

São possíveis neste aparelho oito técnicas polarográficas e voltamétricas (voltamentria de onda quadrada, polarografia de pulso diferencial, polarografia de

RC: 71506

Disponível em: https://www.nucleodoconhecimento.com.br/tecnologia/software-em- 
pulso normal, polarografia DC amostrada, voltametria de redissolução com onda quadrada, voltametria de redissolução com pulso diferencial, voltametria de varredura linear e voltametria cíclica) com possibilidades amplas de mudanças de parâmetros. (EG\&G PARC, 1993)

Este modelo de polarógrafo apresenta outras características como, controle automático de tempos de gotejamento de mercúrio, de agitação e desoxigenação da solução, pré-programação de todas as formas de variação de potencial usadas nas técnicas mais modernas, unidade de disco flexível com capacidade de armazenamento de até nove rotinas diferentes sendo novas programações de potencial, programas de análises, resultados de análises feitas, unidade de tratamento automático de dados, para o traçado da curva de linha de base tangencial e medida automática de altura do pico, armazenamento e subtração automática da curva do branco, armazenamento para comparação automática de curvas de calibração, interfaceamento serial com plotter digital, o que permite apresentar o gráfico e impressão dos resultados de uma análise.

O equipamento tem dois tipos de memórias: uma que chamaremos de imediata e outra que chamaremos de arquivo. Assim, qualquer medida (varredura) é automaticamente armazenada na memória imediata que tem a capacidade para um método completo, isto é, uma curva para o branco, três curvas para os padrões e uma curva para a amostra. Qualquer curva extra além destas (um segundo branco ou amostra ou um quarto padrão) irá apagar a antecessora na memória, sendo que todas serão apagadas quando desligamos o equipamento ou apertamos o botão de "Reset". Assim, para arquivar qualquer curva voltamétrica, deve-se usar a memória arquivo através da tecla de armazenamento ("store"). Armazenando estes dados no disquete interno, com capacidade para 9 curvas e 9 métodos completos, pode-se depois recuperá-los pela tecla de busca ("Recall”).

RC: 71506

Disponível em: https://www.nucleodoconhecimento.com.br/tecnologia/software-em- 
Figura 2. Voltamograma original impresso pelo "plotter".

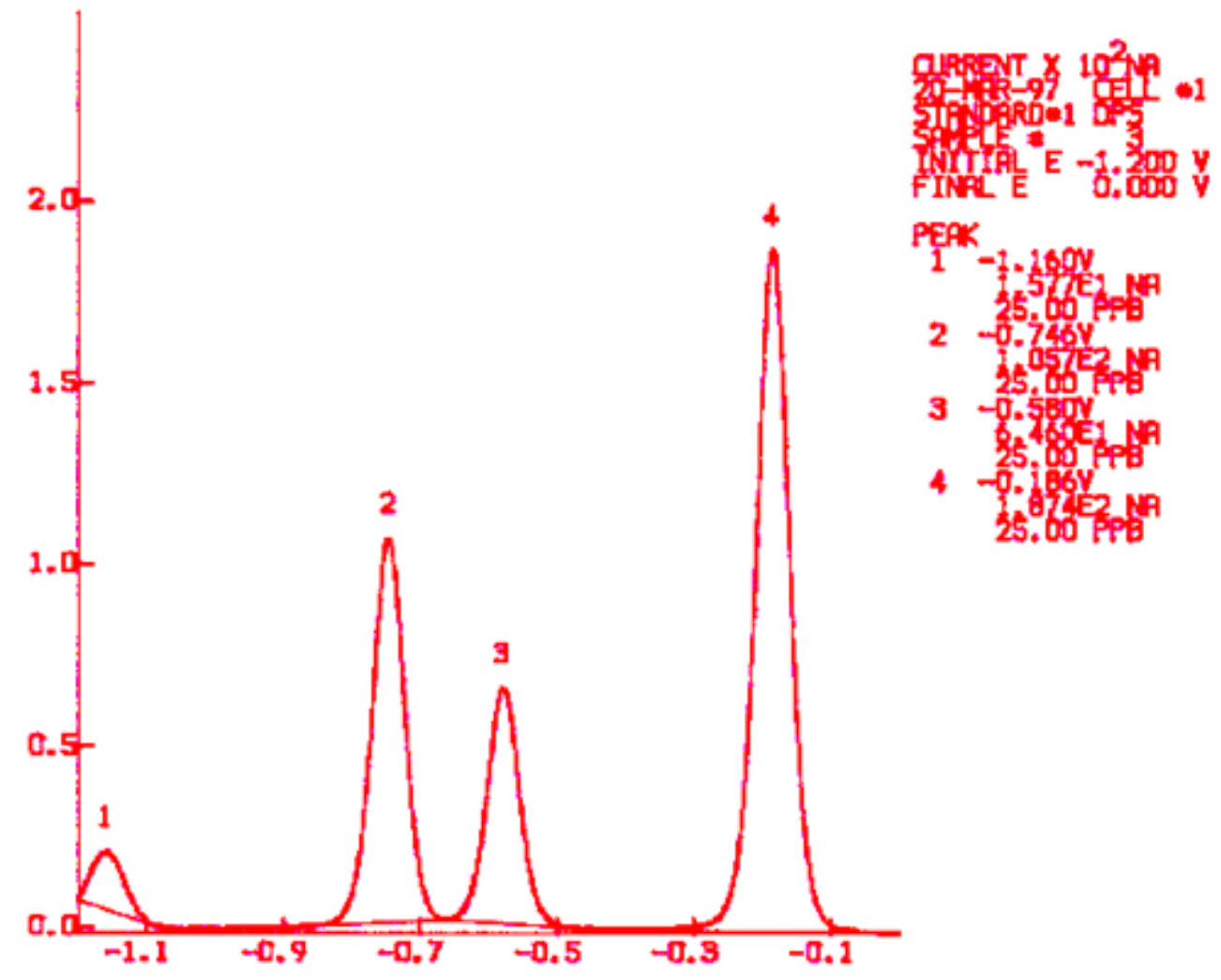

Fonte: Os autores, 2020.

O registro do voltamogramas é feito em papel, mas não é possível registrar todas as correntes ao longo dos picos, o que limita o uso de calibração multivariada, em que se trabalha com todo os dados do voltamograma e não apenas com os valores máximos de cada pico em cada voltamograma. consequentemente, por exemplo, não permite as determinações de componentes com sinais voltamétricos sobrepostos.

Como dito este aparelho tem um potenciostáto robusto, mas com uma eletrônica digital obsoleta, assim o objetivo deste trabalho foi desenvolver um software em VisualBasic para gerenciamento e aquisição dos dados (KELLER et al. 1992;

RC: 71506

Disponível em: https://www.nucleodoconhecimento.com.br/tecnologia/software-emvisualbasic 
O'HAVER, 1991; NEVADO e FLORES, 1992; NUNES, 1996; PIZETA e BRANICA, 1988; RUISÁNCHEZ et al. 1992), via interface serial padrão RS232C, em que os dados podem ser aquisicionados em formato ASCII e processados por vários programas comerciais como por exemplo o Origin. (MICROCAL, 2013)

\section{MATERIAL E MÉTODOS}

\subsection{DESENVOLVIMENTO DO SOFTWARE}

Utilizou-se o editor de VisualBasic versão 5.0, desenvolvendo-se as telas em conformidade com as teclas do painel frontal do polarógrafo. A versão inicial do software foi desenvolvida em Windows 98, mas a versão executável trabalha sem problemas em versões do Windows mais recentes. (PIZETA e BRANICA, 1988)

\subsection{ELETRODOS UTILIZADOS}

Foram utilizados um eletrodo de referência de $\mathrm{Ag} / \mathrm{AgCl}$ em $\mathrm{KCl} 3 \mathrm{~mol} \mathrm{~L} \mathrm{~L}^{-1}$, um eletrodo de platina como eletrodo auxiliar e um eletrodo de mercúrio de gota pendente (HMDE), disponíveis na cela, no modelo 303A (Figura 1B).

\subsection{EXPERIMENTOS EXECUTADOS}

O instrumento interfaceado foi utilizado amplamente em aulas de laboratório de química analítica instrumental para análises de $\mathrm{Cu}(\mathrm{II}), \mathrm{Zn}(\mathrm{II}), \mathrm{Pb}(\mathrm{II})$ e $\mathrm{Cd}(\mathrm{II})$ em sedimentos, solos e águas pela técnica denominada voltametria de redissolução anódica com pulso diferencial e na titulação amperométrica de $\mathrm{Cu}$ (II) com EDTA usando voltametria de onda quadrada. (FENNEMA et al., 1993; HOYLE e THORPE, 1978; PANELI e VOUGARRAPOULOS, 1993; WANG, 1985).

RC: 71506

Disponível em: https://www.nucleodoconhecimento.com.br/tecnologia/software-em- 


\section{RESULTADOS E DISCUSSÃO}

O programa de controle e aquisição de dados do polarógrafo desenvolvido em VisualBasic 5.0, aprimorou não só o uso do polarógrafo, como também possibilitou a migração de todo o processo computacional apresentando diversas vantagens como facilidades de uso e melhor confiabilidade. Algumas dessas diversas vantagens são:

- ambiente visual e orientado a objeto e eventos;

- facilidade de uso;

- possibilidade de escolha da técnica a ser utilizada na análise em tempo de execução;

- possibilidade de salvamento dos parâmetros gerais da análise (parâmetros e técnica) para uso posterior;

- salvamento dos parâmetros gerais da análise atual pelo próprio "software" e não mais pelo polarógrafo;

- escolha do local para o salvamento dos dados da análise.

O primeiro passo no desenvolvimento do aplicativo em VisualBasic foi planejar o que o usuário veria, em outras palavras, desenhar as telas, desta forma, o programa de aquisição e gerenciamento de dados desenvolvido possui as etapas apresentadas a seguir.

- Tela com o título - Tela de inicialização do programa (figura 3).

RC: 71506

Disponível em: https://www.nucleodoconhecimento.com.br/tecnologia/software-em- 
Figura 3. Abertura do software.

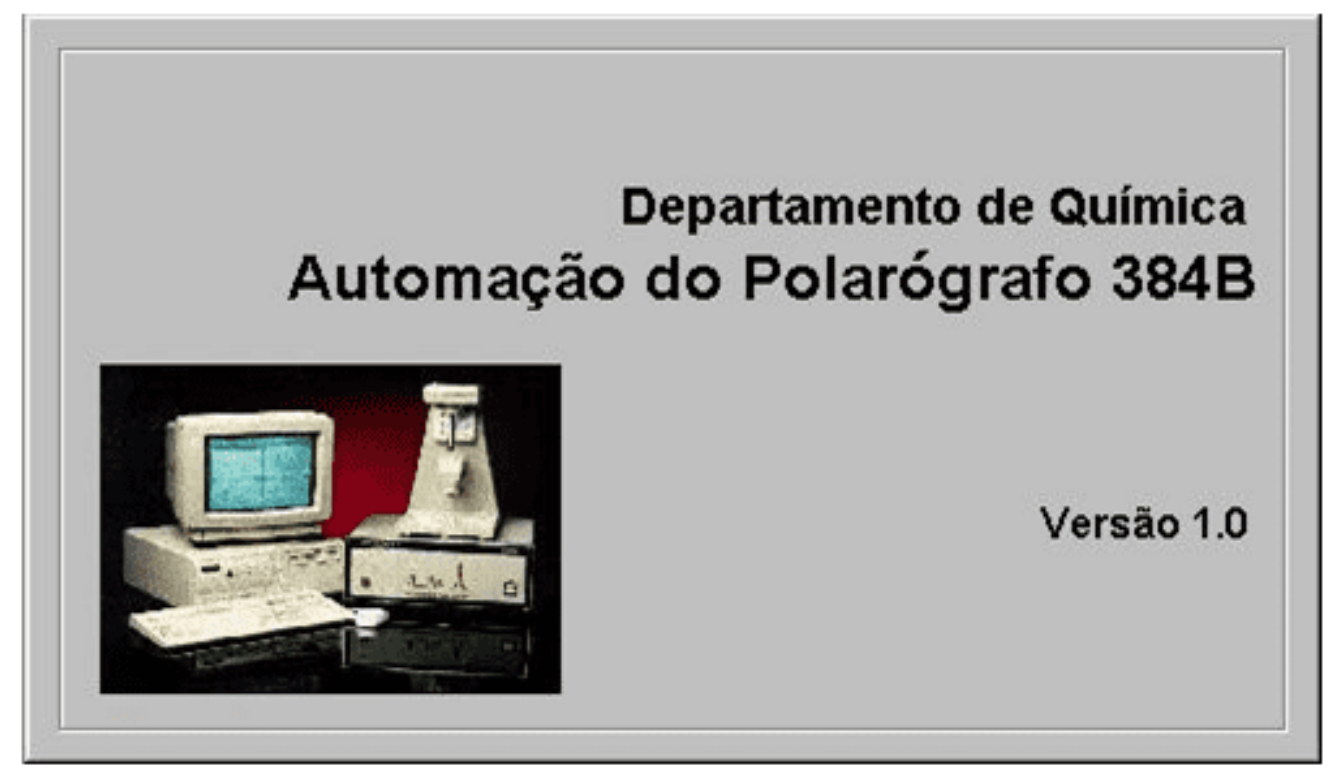

Fonte: Os autores, 2020.

- Tela principal - Tela através da qual se acessa o restante do programa (figura 4).

RC: 71506

Disponível em: https://www.nucleodoconhecimento.com.br/tecnologia/software-emvisualbasic 
Figura 4. Tela de principal do programa.

\section{Automação do Polarógrafo 384B}
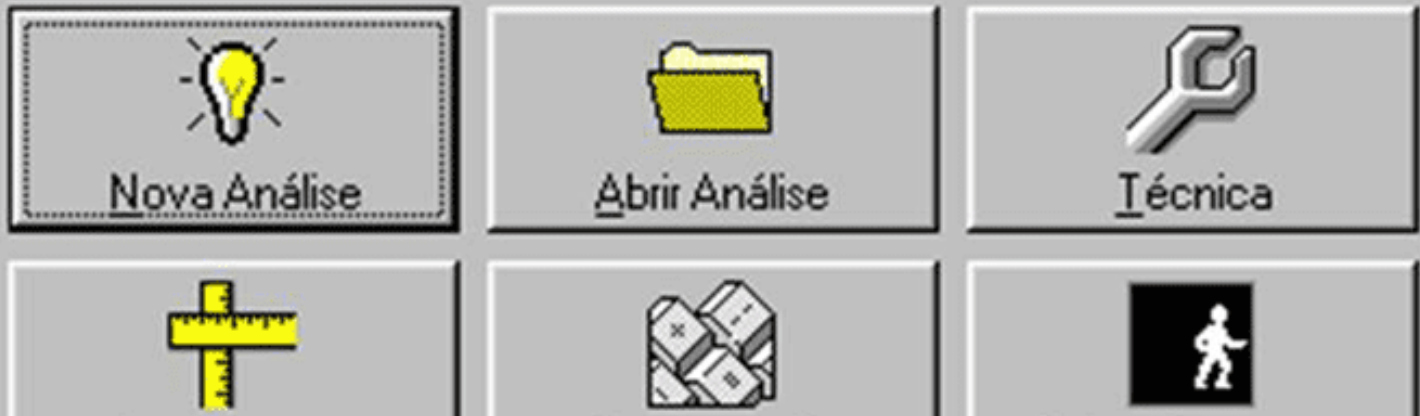

Parâmetros

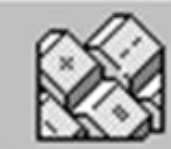

Configuração
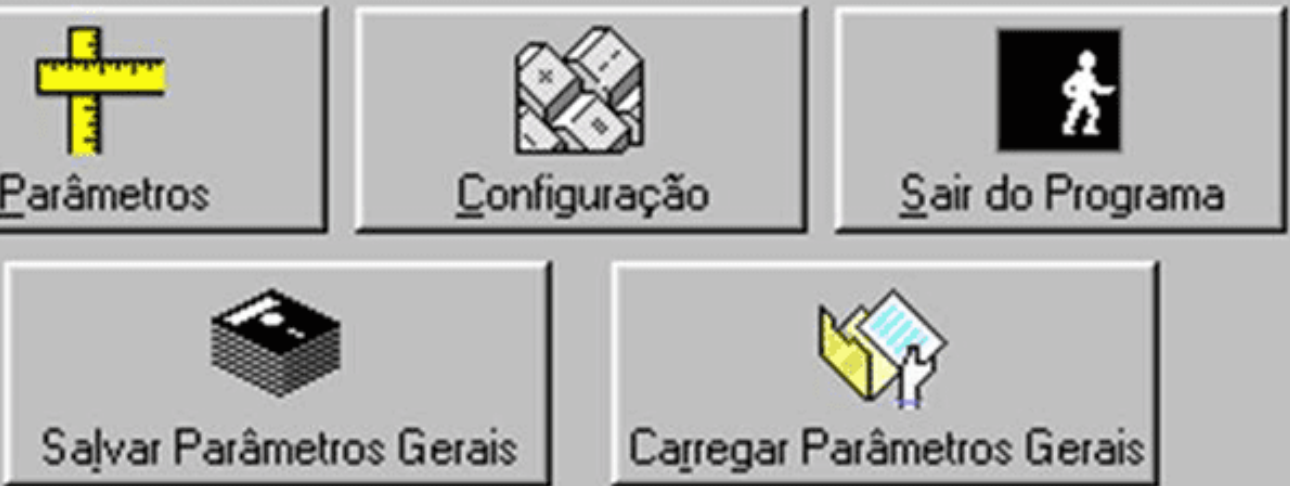

Fonte: Os autores, 2020.

- Tipo da amostra - Nesta tela é feita a escolha do tipo de solução a ser analisada (branco. Amostra ou padrão), através da qual se inicia a análise e também se acessa a tela para definição do local e nome do arquivo para saída de dados (figura 5).

RC: 71506

Disponível em: https://www.nucleodoconhecimento.com.br/tecnologia/software-em- 
Figura 5. Escolha do tipo de analito.

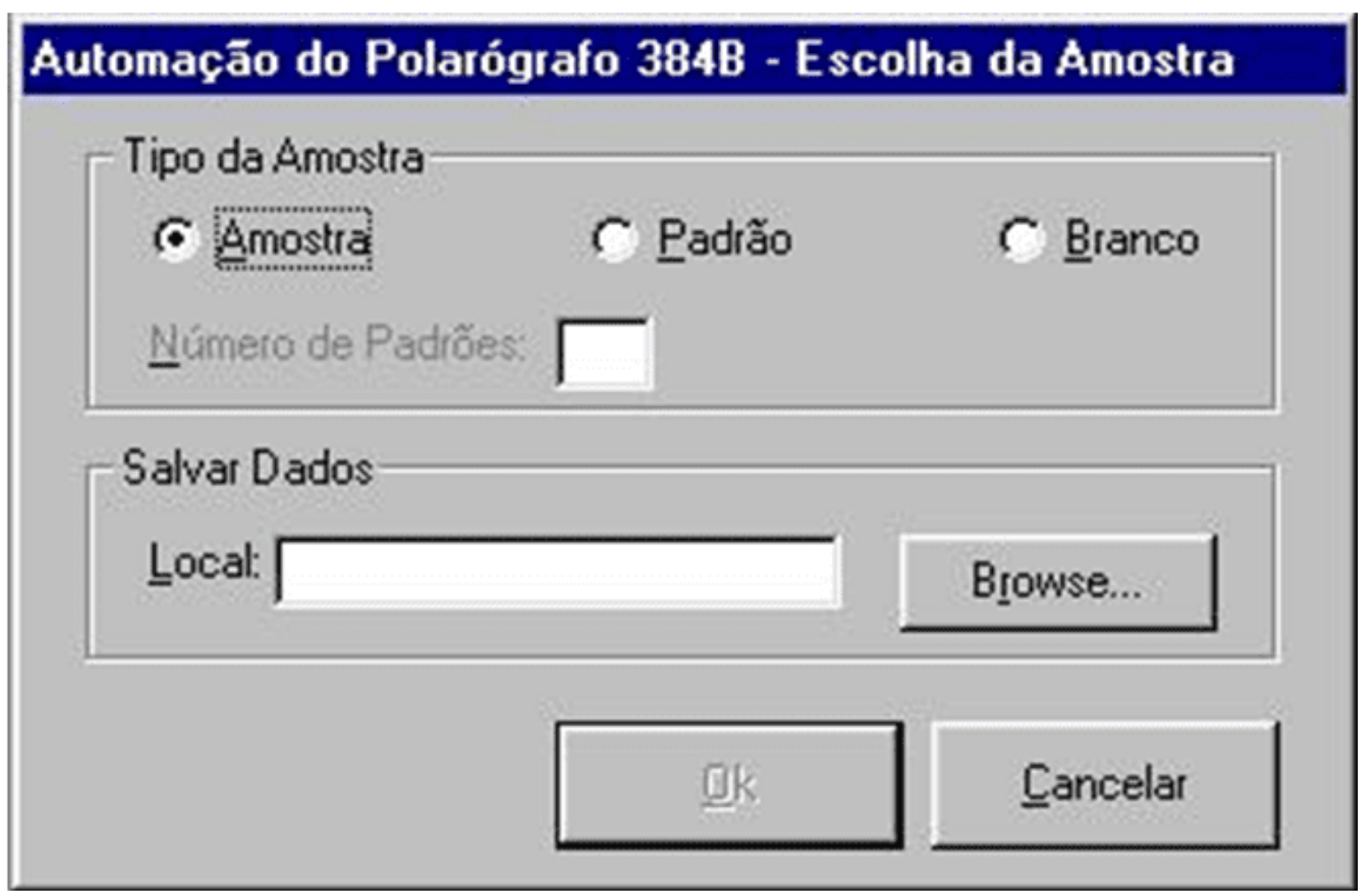

Fonte: Os autores, 2020.

- Escolha do local e nome do arquivo - Tela para definição do local e nome do arquivo para saída dos dados da análise (figura $6 \mathrm{~A}$ ). $\mathrm{O}$ arquivo é salvo no formato ASCII, o que permite a abertura por outros programas.

RC: 71506

Disponível em: https://www.nucleodoconhecimento.com.br/tecnologia/software-emvisualbasic 
Figura 6. Escolha dos locais para salvar os dados (A) e o arquivo de dados (B).

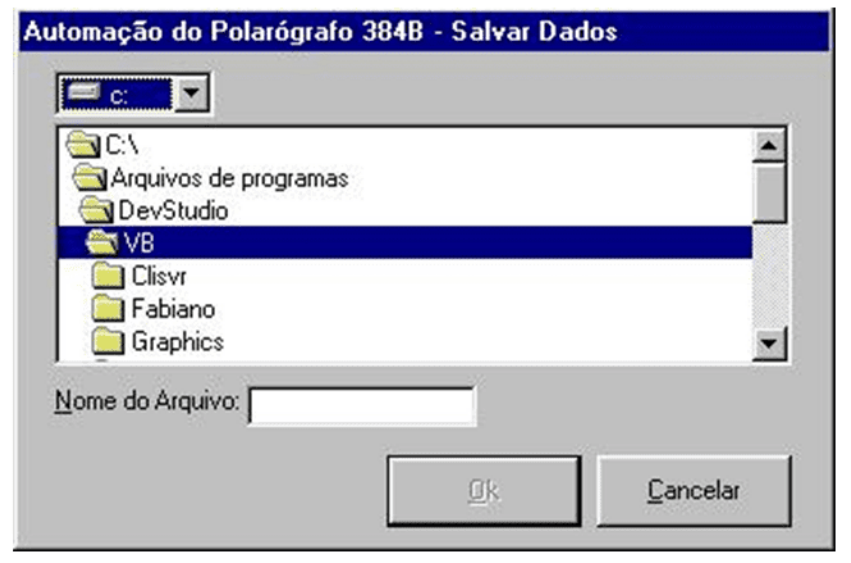

(A)

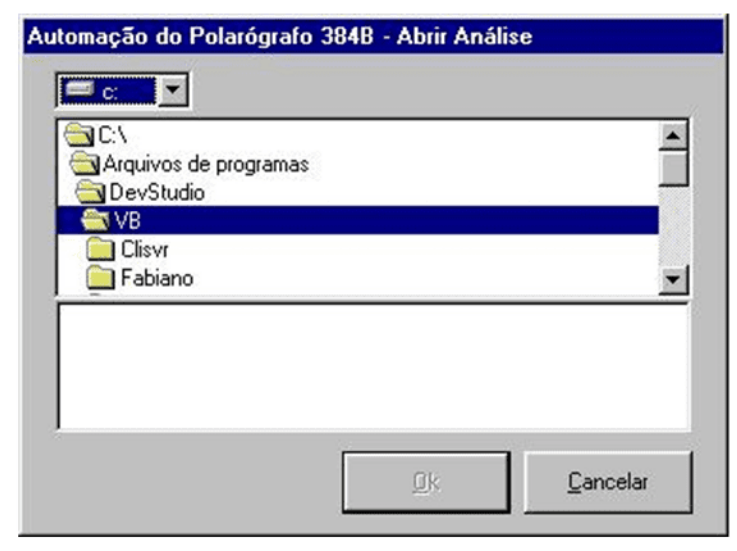

(B)

Fonte: Os autores, 2020.

Abrir análise - Tela para escolha do arquivo de dados, salvo anteriormente, a ser aberto e visualizado (figura 6B). O abrir esta tela são visualizados os dados contidos no arquivo, bem como o voltamograma resultante.

- Técnica de análise - Tela de definição da técnica de análise a ser utilizada pelo polarógrafo (figura 7). Durante a inicialização, o próprio programa já define como técnica de análise aquela que foi anteriormente utilizada.

RC: 71506

Disponível em: https://www.nucleodoconhecimento.com.br/tecnologia/software-em- 
Figura 7. Escolha da técnica voltamétrica.

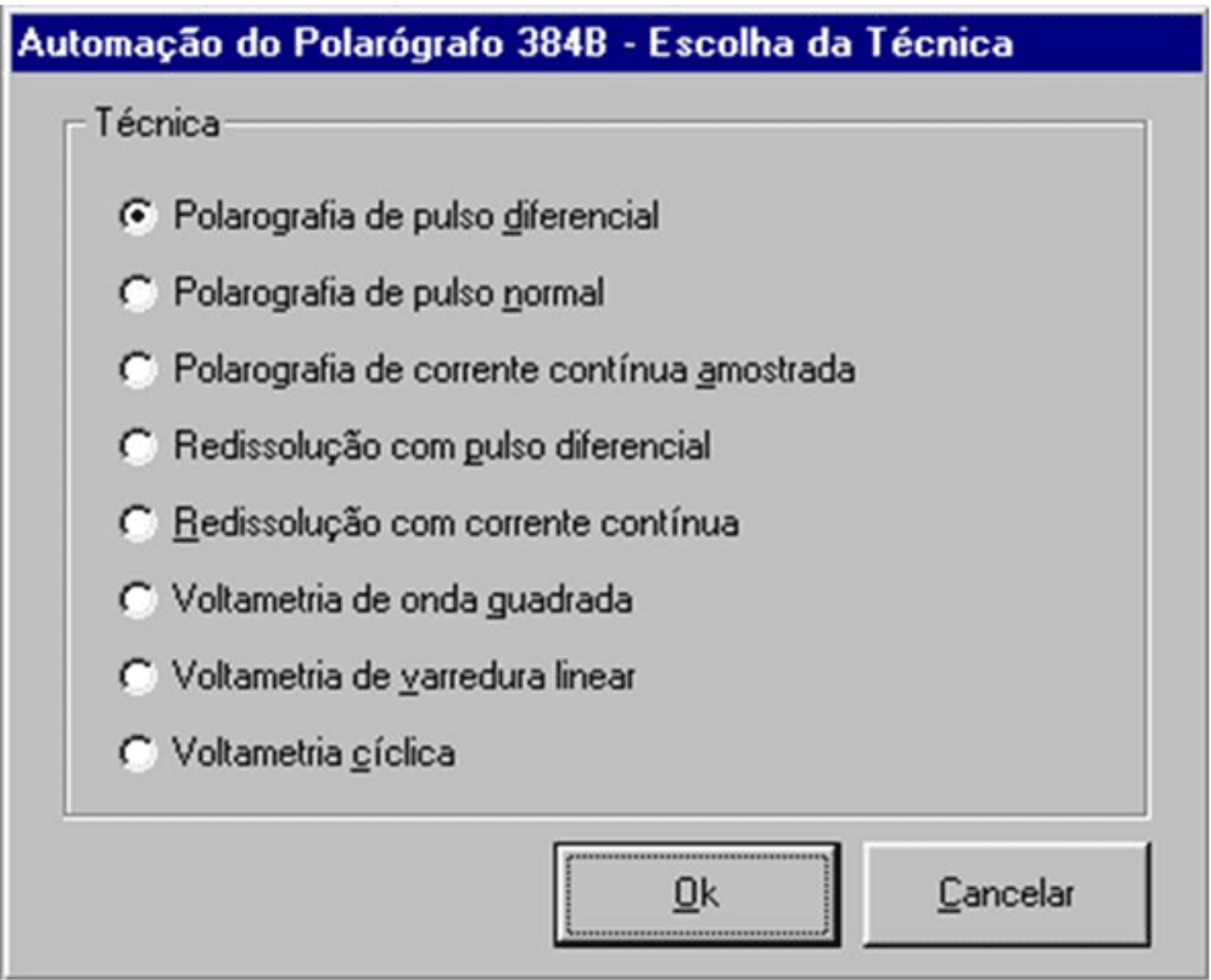

Fonte: Os autores, 2020.

- Parâmetros da análise - Tela de definição dos parâmetros a serem utilizados pelo polarógrafo na nova análise (figura 8A). Durante a inicialização, o próprio programa já carrega os valores dos parâmetros utilizados durante a última análise.

$\mathrm{RC}: 71506$

Disponível em: https://www.nucleodoconhecimento.com.br/tecnologia/software-em- 
Figura 8. Escolha dos parâmetros voltamétricos (A) e de configuração inicial (B)

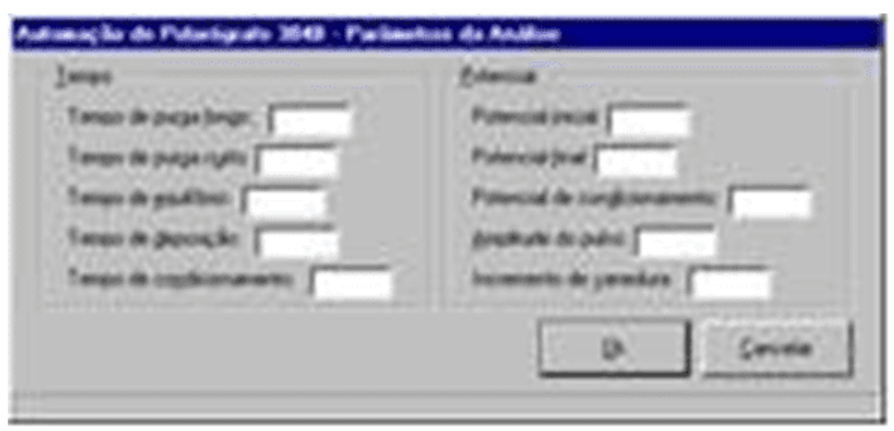

(A)

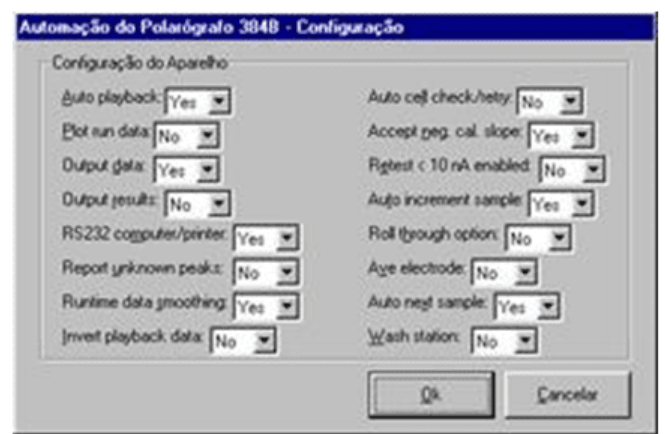

(B)

Fonte: Os autores, 2020.

Configuração do aparelho - Tela de modificação da configuração do aparelho (figura 8B). Durante a inicialização, o próprio programa já carrega a configuração utilizada durante a última análise.

- Salvar parâmetros - Tela de definição do nome do arquivo onde são salvos os parâmetros gerais da análise, técnica a ser utilizada e configuração do aparelho, para uso posterior (figura 9A). Esta função é de grande valia na existência de mais de um usuário que utilizem parâmetros diferentes de análise.

RC: 71506

Disponível em: https://www.nucleodoconhecimento.com.br/tecnologia/software-em- 
Figura 9. Salvar parâmetros da análise (A); carregar parâmetros voltamétricos (B).

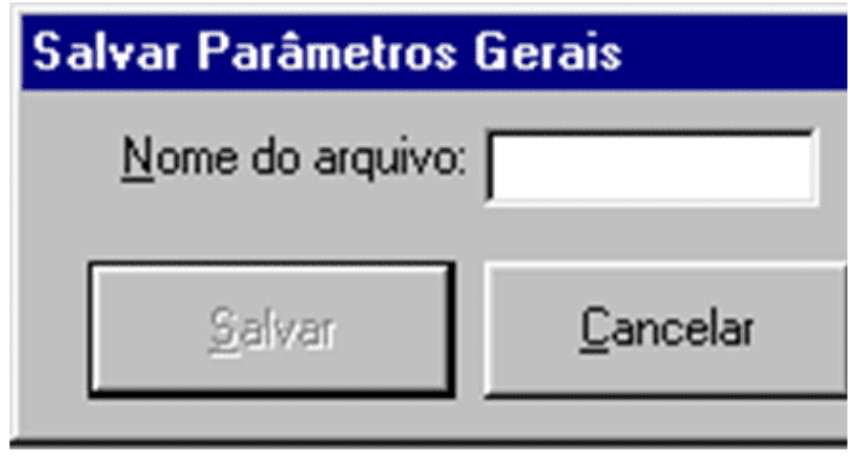

(A)

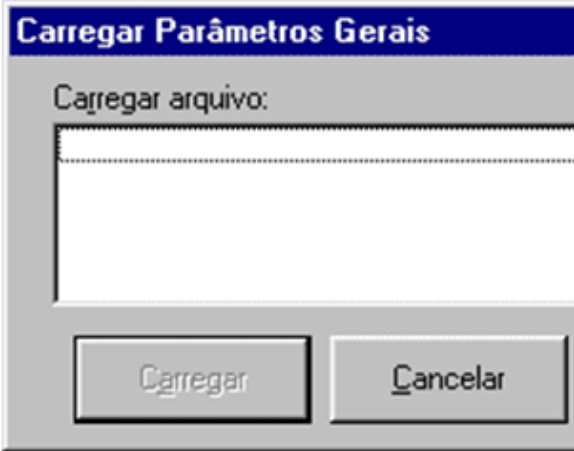

(B)

Fonte: Os autores, 2020.

- Carregar parâmetros - Tela para escolha do arquivo de parâmetros gerais, salvado anteriormente pelo usuário, a ser carregado (figura 9B).

- Polarógrafo executando a varredura - Após efetuar todo o procedimento de passar os parâmetros voltamétricos para o instrumento a coleta de dados é efetuada e logo após os dados são passados ao computador (figura 10A).

Figura 10. Acompanhamento da coleta de dados (A); Finalização do programa (B).

\section{Automação do Polarógrafo 384B}

Coletando dados da análise...

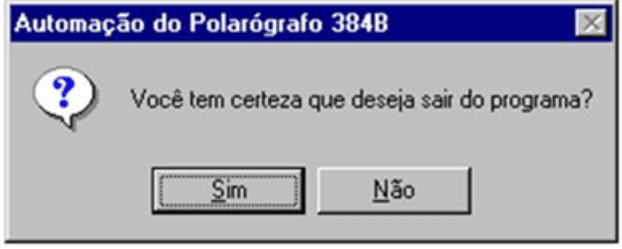

(B)

(A)

Fonte: Os autores, 2020.

- Resultados da Análise - Tela de visualização dos dados da análise, bem como do voltamograma obtido (figura 11). Nesta tela são mostrados o

$\mathrm{RC}: 71506$

Disponível em: https://www.nucleodoconhecimento.com.br/tecnologia/software-em- 
resultado gráfico dos dados obtidos e à esquerda os dados de potencial e corrente.

O interfaceamento do polarógrafo PAR modelo 384B a um microcomputador mostrou-se satisfatório, pois permitiu ao analista uma rápida, completa e segura aquisição de dados. Isto mostra que equipamentos ditos obsoletos podem oferecer, por meio deste recurso, tantas vantagens quanto aqueles mais modernos.

Figura 11. Tela para visualização dos dados voltamétricos coletados.

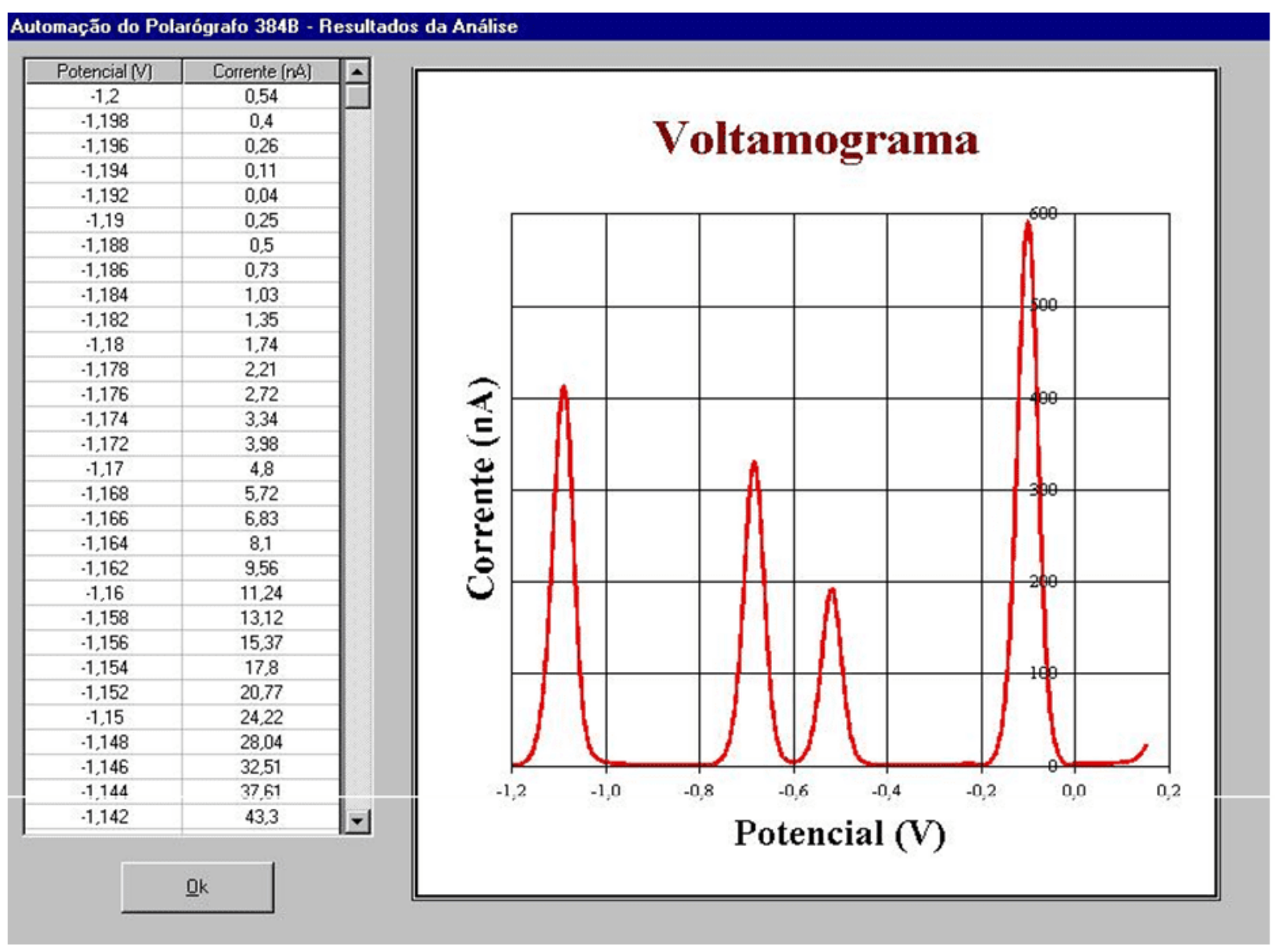

Fonte: Os autores, 2020.

- Tela de finalização do programa - Tela de finalização do programa com pergunta para segurança desta operação (figura 10B).

$\mathrm{RC}: 71506$

Disponível em: https://www.nucleodoconhecimento.com.br/tecnologia/software-em- 
Os exemplos de aplicação em aulas de laboratório foram a determinação de $\mathrm{Cu}(\mathrm{II})$, $\mathrm{Pb}(\mathrm{II}), \mathrm{Cd}(\mathrm{II})$ e $\mathrm{Zn}$ (II) por voltametria de pulso diferencial com redissolução anódica e a titulação amperométrica de $\mathrm{Cu}$ (II) com EDTA usando voltametria de onda quadrada. Nos dois casos o uso do instrumento interfaceado mostrou melhor versatilidade e rapidez em relação ao processo de obtenção de dados quando se trabalha apenas com o polarógrafo não interfaceado.

Foi feito o preparo e varredura do eletrólito de suporte, adicionando à cuba voltamétrica $5 \mathrm{~mL}$ de tampão $\mathrm{H}_{3} \mathrm{CCOOH} / \mathrm{H}_{3} \mathrm{CCOONa} / \mathrm{KCl} \mathrm{pH}=4,5$. Desoxigenou-se a solução com $\mathrm{N}_{2}$ purificado, por 240 segundos, sob agitação magnética, e em seguida fez-se a varredura do potencial inicial ao potencial final. $O$ arquivo foi gravado com Branco.

Procedeu-se à varredura da amostra, acrescentando-se ao eletrólito de suporte, uma alíquota de $100 \mu \mathrm{L}$ de solução amostra contendo os íons metálicos ( $\mathrm{Cu}(\mathrm{II})$, $\mathrm{Pb}(\mathrm{II}), \mathrm{Cd}(\mathrm{II})$ e $\mathrm{Zn}(\mathrm{II})$ a $2,5 \mu \mathrm{g} \mathrm{mL}^{-1}$ ). Desoxigenou-se a solução com $\mathrm{N}_{2}$ (EG\&G PARC, 1980), sob agitação magnética, por 60 segundos e em seguida fez-se a varredura do potencial inicial ao final. $\mathrm{O}$ arquivo foi gravado como Amostra.

No primeiro caso foram estabelecidas as condições experimentais conforme a tabela 1.

Tabela 1. Parâmetros da análise voltamétrica de $\mathrm{Cu}(\mathrm{II}), \mathrm{Pb}(\mathrm{II}), \mathrm{Cd}(\mathrm{II})$ e $\mathrm{Zn}$ (II) por voltametria de pulso diferencial com redissolução anódica.

\begin{tabular}{|l|l|}
\hline Eletrodo de Trabalho & HMDE \\
\hline Eletrodo de Referência & $\mathrm{Ag} / \mathrm{AgCl}$ \\
\hline Eletrodo Auxiliar & Platina \\
\hline Potencial Inicial & $-1,20$ volts \\
\hline Potencial Final & $+0,15$ volts \\
\hline Altura do Pulso & 20 milivolts \\
\hline
\end{tabular}

RC: 71506

Disponível em: https://www.nucleodoconhecimento.com.br/tecnologia/software-em- 


\begin{tabular}{|l|l|}
\hline Incremento de Potencial & 4 milivolts \\
\hline Número de Padrões & 3 \\
\hline Eletrólito de Suporte & Tampão acetato $\mathrm{pH}=4,5$ \\
\hline Tempo de Deposição & 120 segundos \\
\hline Potencial de Deposição & $-1,20$ volts \\
\hline $\begin{array}{l}\text { Tempo de Equilíbrio } \\
\text { Potencial }\end{array}$ & 5 segundos \\
\hline Condicionamento & $+0,15$ volts \\
\hline $\begin{array}{l}\text { Tempo de Condicionamento } \\
\text { Desoxigenação }\end{array}$ & 30 segundos \\
\hline Desoxigenação & 240 segundos para o Eletrólito \\
\hline
\end{tabular}

Fonte: Os autores, 2020.

$\mathrm{Na}$ sequência foi feita as adições do padrão, acrescentando-se à cuba contendo o eletrólito de suporte e a amostra, uma alíquota de $50 \mu \mathrm{L}$ de solução padrão de íons metálicos (Cu(II), $\mathrm{Pb}(\mathrm{II}), \mathrm{Cd}(\mathrm{II})$ e $\mathrm{Zn}(\mathrm{II})$ a $2,5 \mu \mathrm{g} \mathrm{mL} \mathrm{m}^{-1}$ ).

RC: 71506

Disponível em: https://www.nucleodoconhecimento.com.br/tecnologia/software-em- 
Figura 12. Voltamogramas obtidos com os dados aquisicionados e elaborado no Origin (Microcal, 2013).

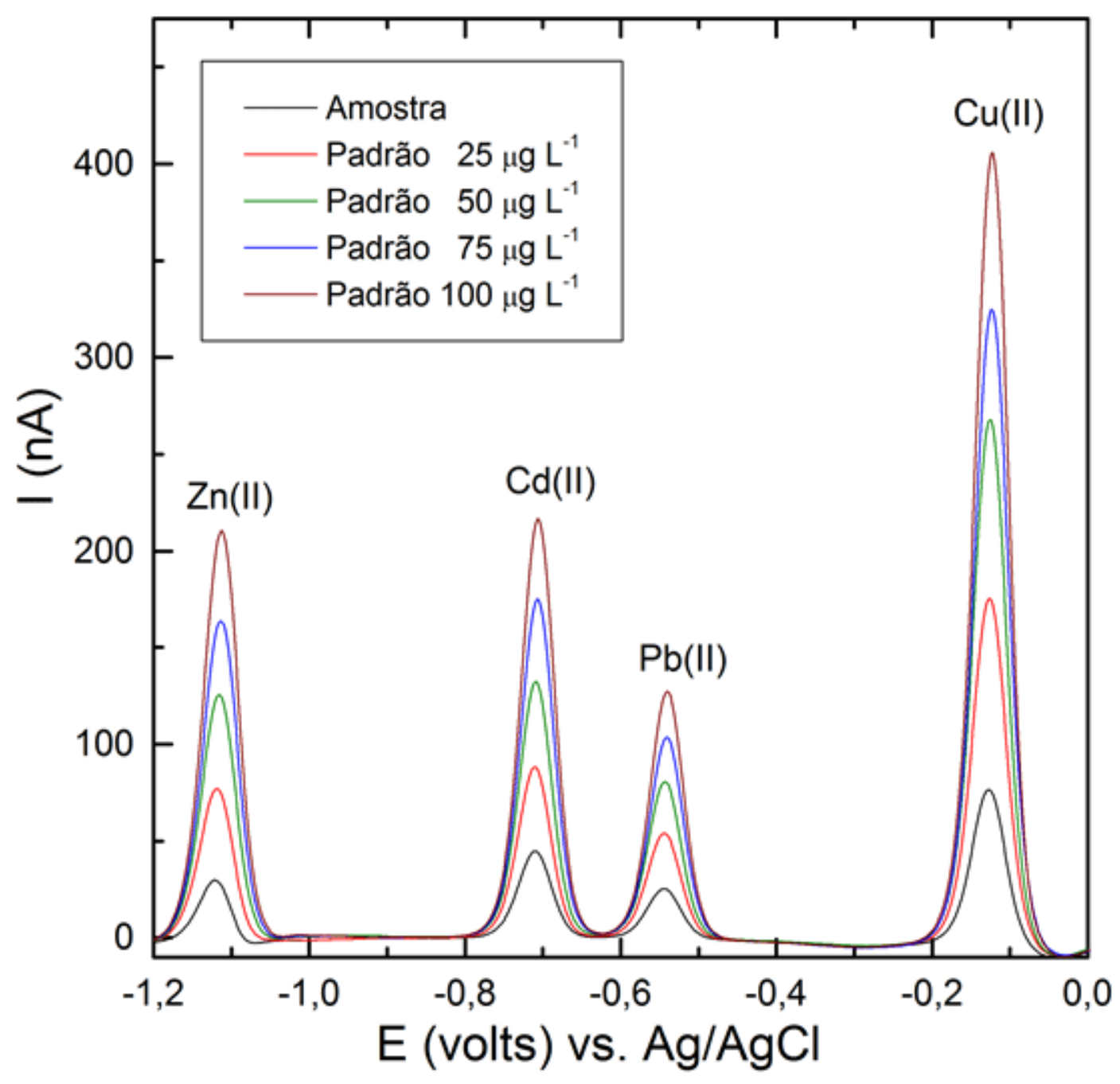

Fonte: Os autores, 2020.

Desoxigenou-se a solução com $\mathrm{N}_{2}$, sob agitação magnética, por 60 segundos e em seguida foi feita a varredura do potencial inicial ao potencial final. $O$ arquivo foi gravado como Padrão-01. Foram feitas mais três adições sucessivas de $50 \mu \mathrm{L}$ da solução padrão. Os arquivos foram gravados como Padrão-02, 03 e 04, respectivamente.

RC: 71506

Disponível em: https://www.nucleodoconhecimento.com.br/tecnologia/software-em- 
Os voltamogramas da amostra e dos padrões foram colocados em um mesmo gráfico (figura 12), importando os dados no formato ASCII para um programa gráfico. $\mathrm{Na}$ sequência foram feitas as quatro curvas de adição de padrão com as correntes máximas produzidas nos potenciais de pico para cada íon metálico em função da concentração do padrão nas cinco medidas feitas (amostra e quatro padrões), calculando-se a concentração de cada íon na amostra (figura 13).

Figura 13. Curvas de adições de padrão para $\mathrm{Cu}(\mathrm{II}), \mathrm{Pb}(\mathrm{II}), \mathrm{Cd}(\mathrm{II})$ e $\mathrm{Zn}(\mathrm{II})$.
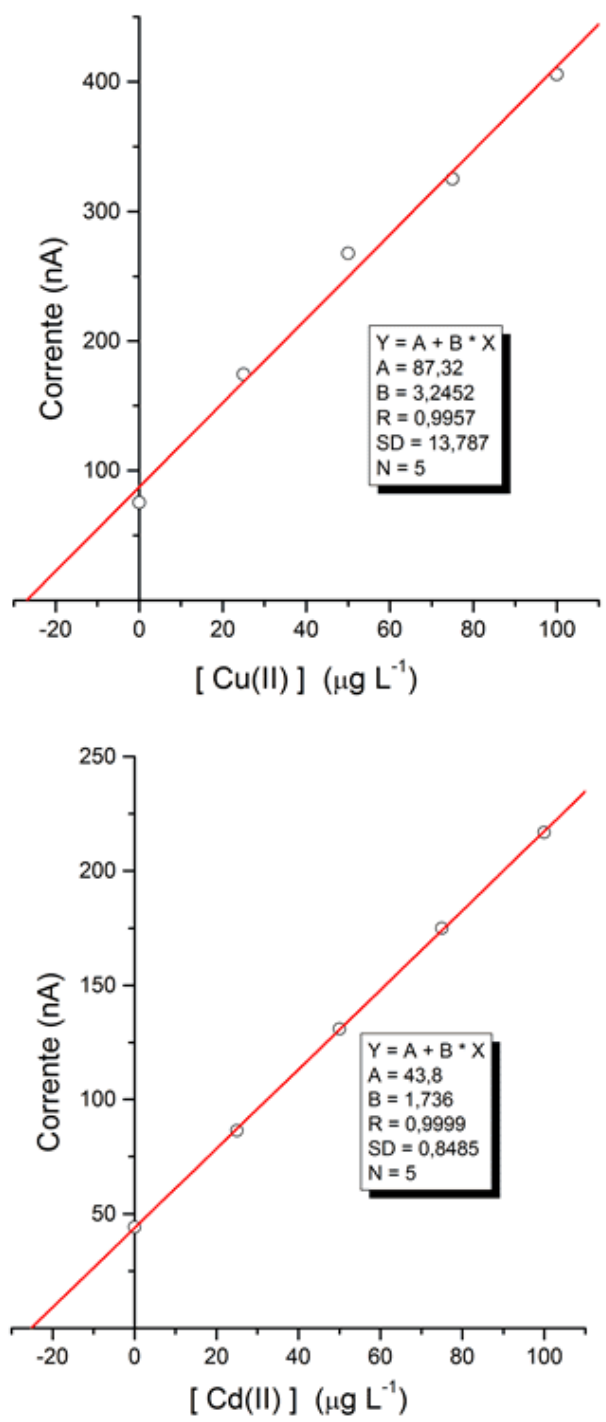
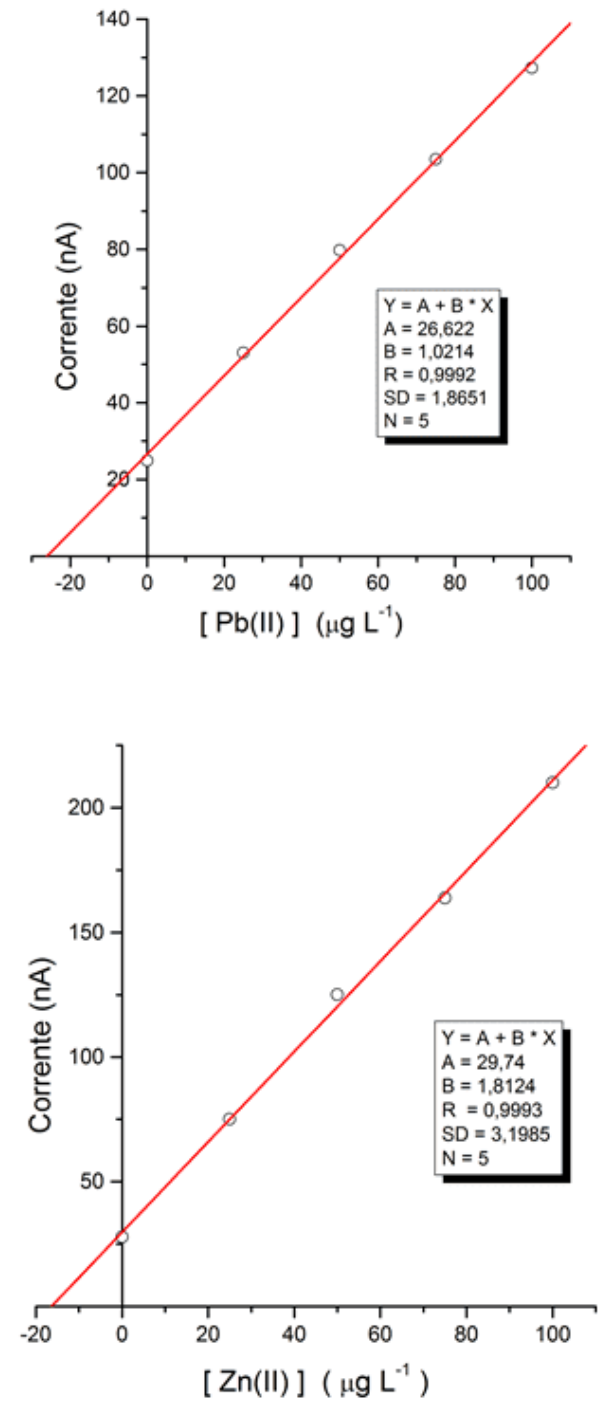

Fonte: Os autores, 2020.

RC: 71506

Disponível em: https://www.nucleodoconhecimento.com.br/tecnologia/software-em- 
No segundo caso, na titulação amperométrica de $\mathrm{Cu}$ (II) com EDTA, usando voltametria de onda quadrada, foram estabelecidas as condições experimentais conforme a tabela 2.

Tabela 2. Parâmetros da titulação voltamétrica de $\mathrm{Cu}$ (II) com EDTA por voltametria de onda quadrada.

\begin{tabular}{|l|l|}
\hline Eletrodo de Trabalho & HMDE \\
\hline Eletrodo de Referência & $\mathrm{Ag} / \mathrm{AgCl}$ \\
\hline Eletrodo Auxiliar & Platina \\
\hline Potencial Inicial & $+0,50$ volts \\
\hline Potencial Final & $-0,50$ volts \\
\hline Altura do Pulso & 20 milivolts \\
\hline Incremento de Potencial & 4 milivolts \\
\hline Eletrólito de Suporte & Tampão Acetato pH=4,5 \\
\hline Tempo de Equilíbrio & 10 segundos \\
\hline Potencial & $+0,50$ volts \\
Condicionamento & \\
\hline Tempo de Condicionamento & 30 segundos \\
\hline Desoxigenação & 240 s para o Eletrólito \\
\hline Desoxigenação & 60 s entre adições \\
\hline
\end{tabular}

Fonte: Os autores, 2020.

Foi feito o preparo e varredura do eletrólito de suporte, adicionando-se à cuba voltamétrica $5 \mathrm{~mL}$ de tampão $\mathrm{H}_{3} \mathrm{CCOOH} / \mathrm{H}_{3} \mathrm{CCOONa} / \mathrm{KCl} \mathrm{pH=4,5}$. Desoxigenou-se a solução com $\mathrm{N}_{2}$ purificado, por 240 segundos, sob agitação magnética, e em seguida fez-se a varredura do potencial inicial ao potencial final. $O$ arquivo foi gravado com Branco.

RC: 71506

Disponível em: https://www.nucleodoconhecimento.com.br/tecnologia/software-em- 
Procedeu-se à varredura da amostra, acrescentando-se ao eletrólito de suporte, uma alíquota de $200 \mu \mathrm{L}$ de solução padrão de $\mathrm{Cu}(\mathrm{II})$ a $1000 \mu \mathrm{g} \mathrm{mL}^{-1}(0,0157 \mathrm{~mol} \mathrm{~L}$ 1), que serviu como amostra. Desoxigenou-se a solução $\operatorname{com~} \mathrm{N}_{2}$, sob agitação magnética, por 60 segundos e em seguida foi feita a varredura do potencial inicial ao potencial final. $\mathrm{O}$ arquivo foi gravado como Amostra.

$\mathrm{Na}$ sequência foi feita as adições do complexante EDTA, acrescentando-se à cuba contendo o eletrólito de suporte e a amostra, uma alíquota de $50 \mu \mathrm{L}$ de solução padrão $0,01 \mathrm{~mol} \mathrm{~L}^{-1}$ de EDTA. Desoxigenou-se a solução com $\mathrm{N}_{2}$, sob agitação magnética, por 60 segundos e em seguida foi feita a varredura do potencial inicial ao potencial final. $O$ arquivo foi gravado como EDTA-01. Foram feitas mais doze adições sucessivas de $50 \mu \mathrm{L}$ da solução de EDTA. Os arquivos foram gravados como EDTA-02 a EDTA-13, respectivamente.

Figura 14. Voltamogramas da titulação de $\mathrm{Cu}$ (II) com EDTA (A); Curva de titulação de $\mathrm{Cu}$ (II) com EDTA elaborada com os máximos de corrente dos voltamogramas (B).

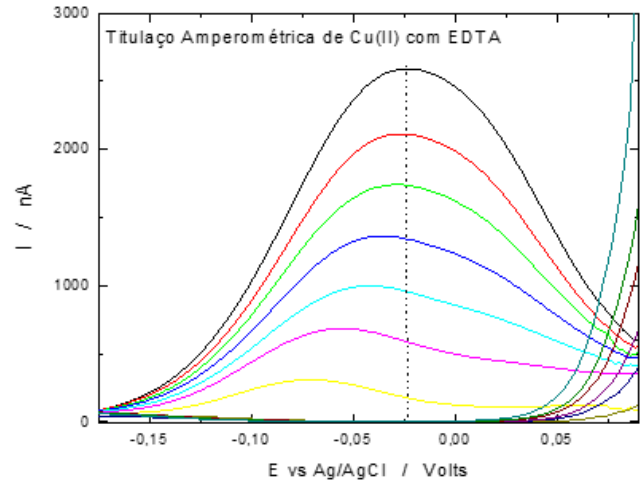

(A)

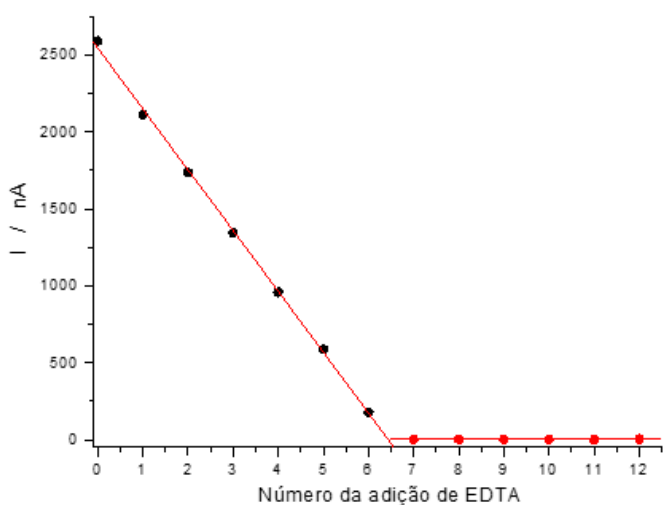

(B)

Fonte: Os autores, 2020.

Os voltamogramas da amostra e das doze adições de EDTA foram colocados em um mesmo gráfico, importando os dados no formato ASCll para um programa gráfico (figura 14A). Foi feita a curva de titulação do Cobre(II) com o titulante EDTA,

RC: 71506

Disponível em: https://www.nucleodoconhecimento.com.br/tecnologia/software-em- 
com as correntes máximas produzidas nos potenciais de pico para cada voltamograma em função do volume de EDTA adicionado (figura 14B). Desta forma foi possível calcular e confirmar a relação molar do complexo entre Cobre(II) e EDTA, igual a 1:1.

\section{CONCLUSÕES}

O software desenvolvido na linguagem VisualBasic para controle e aquisição de dados do polarógrafo PAR modelo 384B, mostrou-se satisfatório, pois permitiu aquisição segura dos dados. Este aparelho, apesar de obsoleto em termos de eletrônica digital, apresenta na parte analógica, um potenciostáto robusto que permitiu, com este interfaceamento, prolongar a vida útil do mesmo. Com este recurso o aparelho apresentou tantas vantagens quanto aqueles mais modernos.

Isto tornou possível usá-lo em aulas de laboratório de química analítica instrumental na determinação de $\mathrm{Cu}(\mathrm{II}), \mathrm{Pb}(\mathrm{II}), \mathrm{Cd}(\mathrm{II})$ e $\mathrm{Zn}(\mathrm{II})$ por voltametria de pulso diferencial com redissolução anódica e a titulação amperométrica de $\mathrm{Cu}$ (II) com EDTA usando voltametria de onda quadrada. Nestes casos o uso do instrumento interfaceado mostrou melhor versatilidade e rapidez em relação ao processo de obtenção de dados quando se trabalha apenas com o polarógrafo não interfaceado.

\section{REFERÊNCIAS}

EG\&G PARC, Deaeration ... Why and How, Application Note D-2. 1980, 3p.

EG\&PARC, Model 384B-ES Educational System - Instruction Manual. Princeton, 1993, 113p.

FENNEMA, B. D.J.R., FORSTER, R.J., VOZ, J.G., HUGHES, G., DIAMOND, D. Obtaining and processing data from laboratory instruments. Analytical Chemistry, 12(1); 1993: 1-3.

$\mathrm{RC}: 71506$

Disponível em: https://www.nucleodoconhecimento.com.br/tecnologia/software-em- 
HOYLE, W. C., THORPE, T. M. XCVII. Pulse Polarografhy: A series of Student Experiments. Journal of Chemical Education, 55; 1978: A229-A233.

KELLER, H. R.; AGUIAR, P. F.; MASSART, D. L. Simulations of analytical processes using visual basic. Analytical Chemistry, 11(4); 1992: 131-133.

MICROCAL, Origin 9.0, Microcal, Northampton, MA, 2013.

NEVADO, J. J. B., FLORES, R. Use of a data treatment software for the resolution of overlapping differential pulse polarographic peaks. Analitical Chemistry, 342; 1992: 273-275.

NUNES, E. Microsoft VisualBasic. Versão 4.0. MAKRON Books do Brasil Editora Ltda., 1996. 348p.

O'HAVER, T. C. An introduction to signal processing in chemical measurement. Journal of Chemical education, 68(6); 1991: 147-150.

PANELI, M. G., VOUGARAPOULOS, A. Applications of adsorptive stripping voltammetry in the determination of trace and ultratrace metais. Electroanalysis, 5; 1993: 355-373.

PIZETA, I., BRANICA, M. Computer automation of polarographic analyzer par 384B and development of specific implementation software. J. Electroanal. Chem., 250; 1988: 293-299.

RUISÁNCHEZ, I., LARRECHI, M. S., RIUS, F. X. computer-Aided voltammetric method development employing a knowledge-based expert system. Analytical Chemistry, 11(4); 1992: 135-142.

WANG, J. Stripping analysis principles, instrumentation and applications. Vch Pub, 1985, 160p.

RC: 71506

Disponível em: https://www.nucleodoconhecimento.com.br/tecnologia/software-em- 
Enviado: Novembro, 2020.

Aprovado: Dezembro, 2020.

RC: 71506

Disponível em: https://www.nucleodoconhecimento.com.br/tecnologia/software-emvisualbasic 